\title{
Microstructure-Property Relationship in Advanced Ni-Based Superalloys
}

\author{
Hiroto Kitaguchi
}

Additional information is available at the end of the chapter

http://dx.doi.org/10.5772/52011

\section{Introduction}

$\mathrm{Ni}$ based superalloys have been developed more or less empirically over the past 60 years from a simple Ni-Cr matrix to the present multi element and phase systems[1], having a fully austenitic face centred cubic (fcc) structure which maintains a superior tensile, fatigue and creep properties at high temperature to a body centred cubic (bcc) alloy[1]. One of the major applications of $\mathrm{Ni}$ superalloys is gas turbine engines. They comprise over $50 \%$ of the weight of advanced aircraft engines and include wrought and cast turbine blades and powder metallurgy $(\mathrm{P} / \mathrm{M})$ route turbine discs [1].

One of the most important goals of engine design is increasing turbine entry temperature (TET): the temperature of the hot gases entering the turbine arrangement [2]. This implies that the resistance against the environmental attack, i.e. high temperature, under a severe mechanical force is the priority challenge and indeed $\mathrm{Ni}$ based superalloys are used in the hottest as well as the highest tensile pressure of the gas turbine engine component as shown in the schematic diagram in Fig. 1. Nowadays, for the advanced cast single crystal superalloys in the turbine blades, the alloy capability exceeds $1,000^{\circ} \mathrm{C}$ [2]. In this chapter, the polycrystalline Ni superalloys, which have slightly less temperature capability up to $800^{\circ} \mathrm{C}$, applied in the turbine discs and the adjoined shafts, will be introduced focusing on their microstructures correlating with the mechanical properties.

\section{Microstructure (second phases)}

\subsection{Hardening precipitates}

From the point of view of microstructure, Ni superalloys are complex [4]. The fcc matrix, known as $\gamma$, mainly consists of nickel, cobalt, iron, chromium and molybdenum. The strength of superalloys are conferred by the hardening precipitates known as $\gamma^{\prime}$ (Ni3Al based L12 


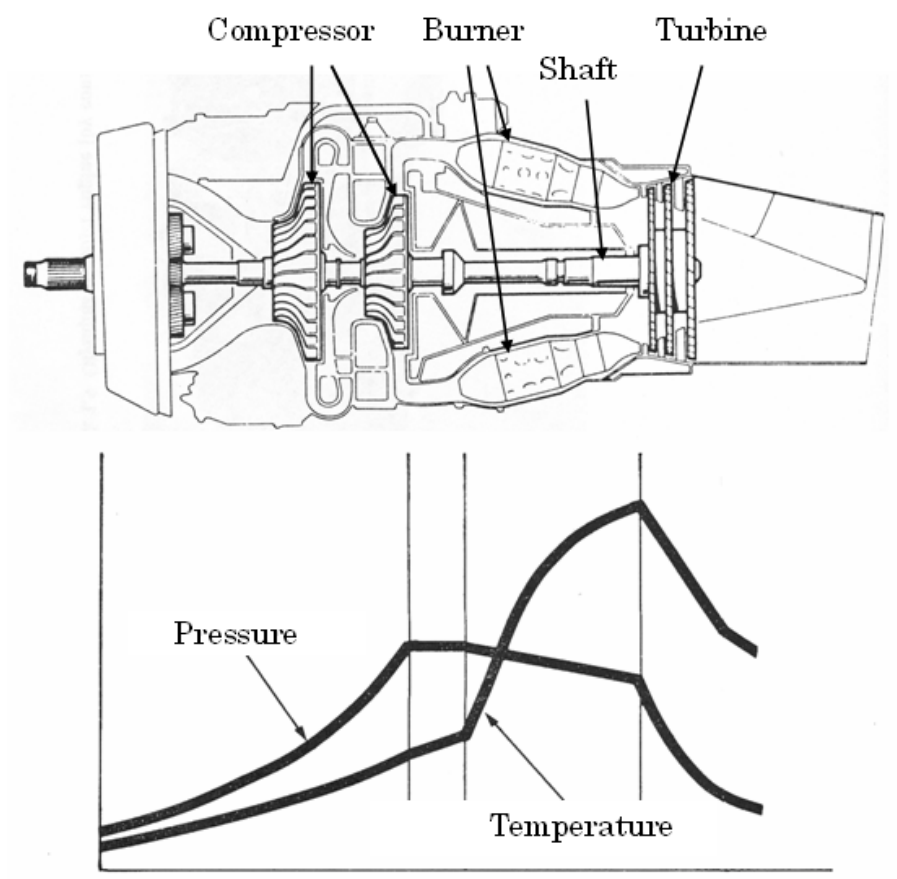

Figure 1. (a) Schematic diagram of a turbine engine Ref. [3]. (b) Schematic diagram of the temperature and pressure gradients throughout the engine component correlating with the diagram (a) Ref. [4]

structure) (Fig. 2). In some nickel - iron superalloys such as IN718 and IN706, which contain niobium, they are hardened by $\gamma^{\prime \prime}$ ( $\mathrm{Ni}_{3} \mathrm{Nb}$ based $\mathrm{D}_{22}$ structure) (Fig. 3) [2]. Homogeneously distributed coherent hardening precipitates confer excellent tensile and fatigue life properties at high temperatures. Their volume fraction is controlled by the nominal chemical composition. The size and the morphology are controlled by the process and their crystallographic relations with $\gamma$ matrix. The precipitates arise close to the solvus temperature grow larger which subsequently restrict the grain growth pinning grain boundaries (Fig. 4). On the other hand, the precipitates arise at lower temperature such as during cooling after heat treatment stay small (Fig. 4 (left hand side of the image)). $\gamma^{\prime}$ has the perfect coherency with the $\gamma$ matrix, hence their morphologies are mostly sphere, whereas $\gamma^{\prime \prime}$ has a tall crystal unit tetragonal structure where $a$ axis has the identical lattice parameter with the $\gamma$ matrix but $c$ axis has nearly double the length of the $\gamma$, hence $\gamma^{\prime \prime}$ always precipitate with the perfect coherency on the basal plane with $\gamma$ and grow along the longitudinal direction (Fig. 5).

\subsection{Carbides and borides}

Carbon and boron are added as a grain boundary strengthener by segregating in the grain boundaries and forming carbides and borides. They are believed to be formed during solidification, aging treatment which strengthen grain boundaries at elevated temperatures 
but the ones arising during service must be controlled carefully since they can impair properties [4].

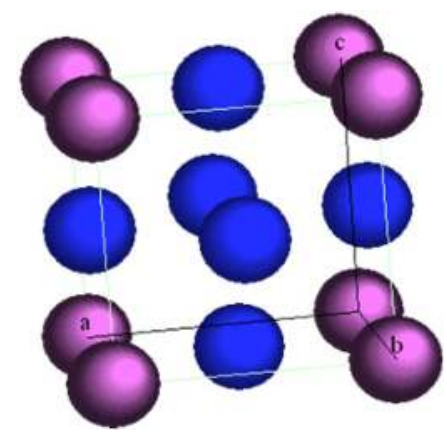

Figure 2. $\gamma^{\prime} \mathrm{L}_{2}$ structure. Ni atoms are blue and Al purple

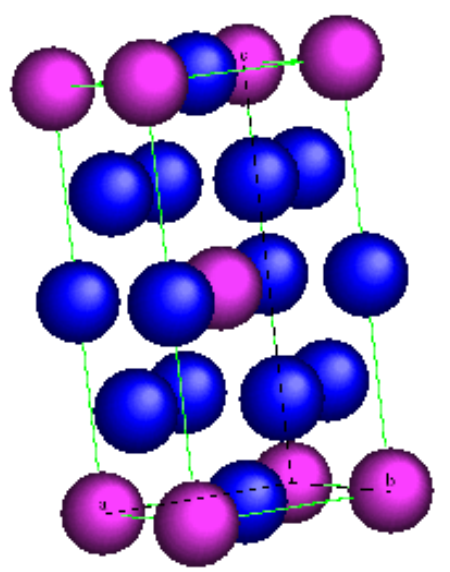

Figure 3. $\gamma^{\prime \prime} \mathrm{D}_{22}$ structure. $\mathrm{Ni}$ atoms are blue and $\mathrm{Nb}, \mathrm{Al}$ and Ti purple

Carbides are traditionally classified by their chemical composition, mainly $\mathrm{MC}, \mathrm{M}_{6} \mathrm{C}$ and $\mathrm{M}_{23} \mathrm{C}_{6}$, where $\mathrm{M}$ stands for metal elements such as $\mathrm{Ti}, \mathrm{Cr}, \mathrm{Nb}, \mathrm{Mo}$, Hf and Ta [4].

MC carbides are usually coarse (Fig. 6), having a fcc densely packed structure [4]. Ti, Nb, Hf and $\mathrm{Ta}$ are the main metal elements. They are very strong and are normally considered to be some of the most stable compounds in nature, justified by their high precipitation and melting temperature: they are believed to precipitate during processing shortly after solidification of the superalloy [4]. They usually have little or no orientation relationship with the alloy matrix [4].

$\mathrm{M}_{6} \mathrm{C}$ carbides have a complex cubic structure and they precipitate when the alloy contains highly refractory elements, for example Mo and W. These carbides are believed to be the product of $\mathrm{MC}$ carbide decomposition during service or relatively high heat treatment between 815 and $980^{\circ} \mathrm{C}$ [4]. The examples of the micrographs of $\mathrm{M}_{6} \mathrm{C}$ can be found in Ref. $[5,6]$. 


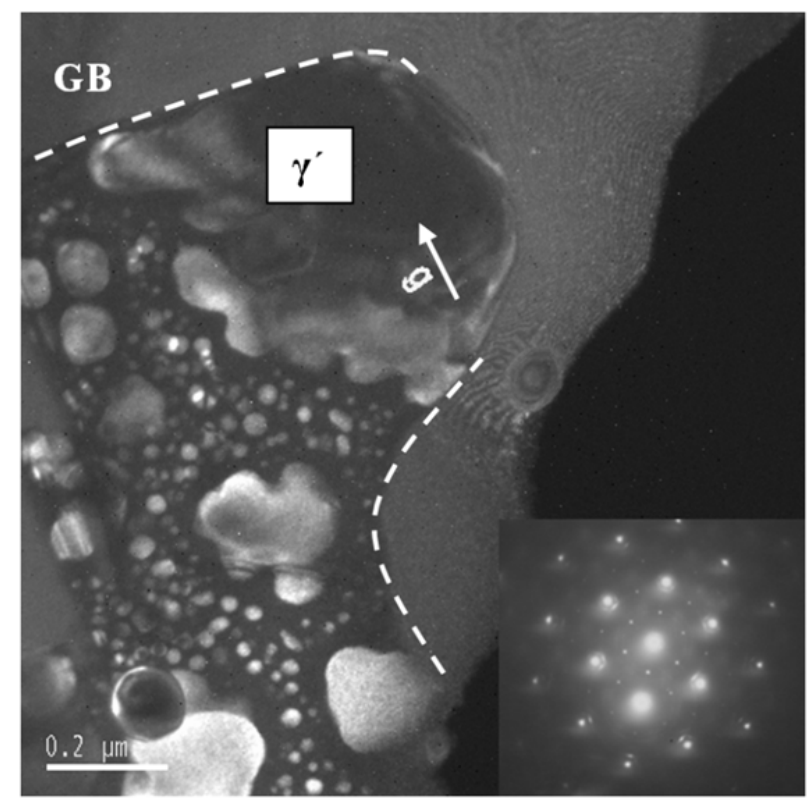

Figure 4. TEM dark field (DF) image. $\gamma^{\prime}$ pinning grain boundary, shown by the white dashed line. The small spherically shaped precipitates inside the grain are also $\gamma^{\prime} \cdot(g=01 \overline{1} \quad B=[111])$

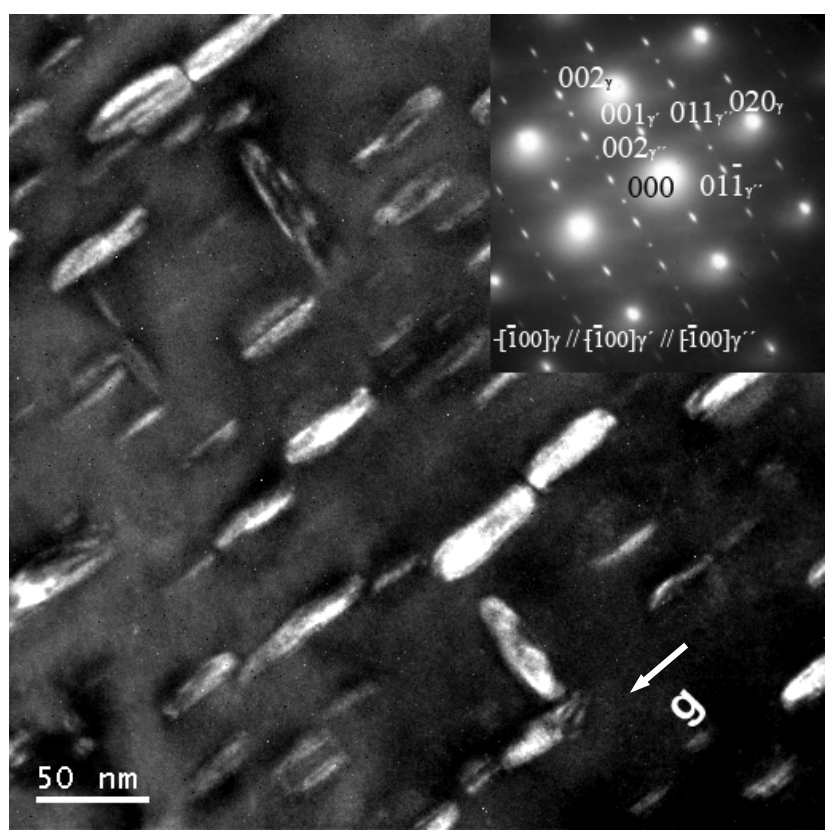

Figure 5. TEM DF image of the $\gamma^{\prime \prime}$ in IN718. The growth direction is c axis parallel to the a axis of $\gamma($ $\left.\left(\mathrm{g}_{\gamma^{\prime \prime}}=0 \begin{array}{lll}0 & 0 & 2\end{array}\right) \mathrm{B}=[100]\right)$. 


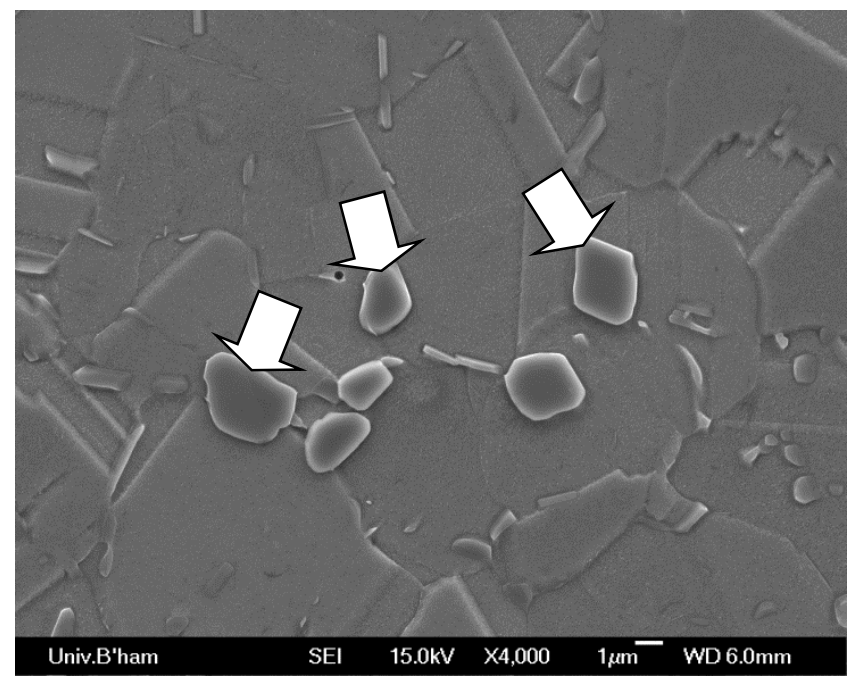

Figure 6. Coarse $\mathrm{Nb}$ and $\mathrm{Ti}$ based carbide in IN718

$\mathrm{M}_{23} \mathrm{C}_{6}$ carbides (Fig. 7) form mainly along grain boundaries at a relatively low temperature for carbides: between 760 and $980^{\circ} \mathrm{C}$. The crystal structure is complex cubic structure. The lattice parameter is exactly three times larger than $\gamma$ matrix, hence they precipitate with cubecube orientation with the matrix (Fig. 8). They are believed to form either by the decomposition of $\mathrm{MC}$ or $\mathrm{M}_{6} \mathrm{C}$ or they nucleate directly on the grain boundaries. They are known as having a high content of $\mathrm{Cr} . \mathrm{M}_{23} \mathrm{C}_{6}$ carbides have a significant effect on $\mathrm{Ni}$ based superalloy properties [4] since they are profuse in alloys with moderate to high Cr content [4]

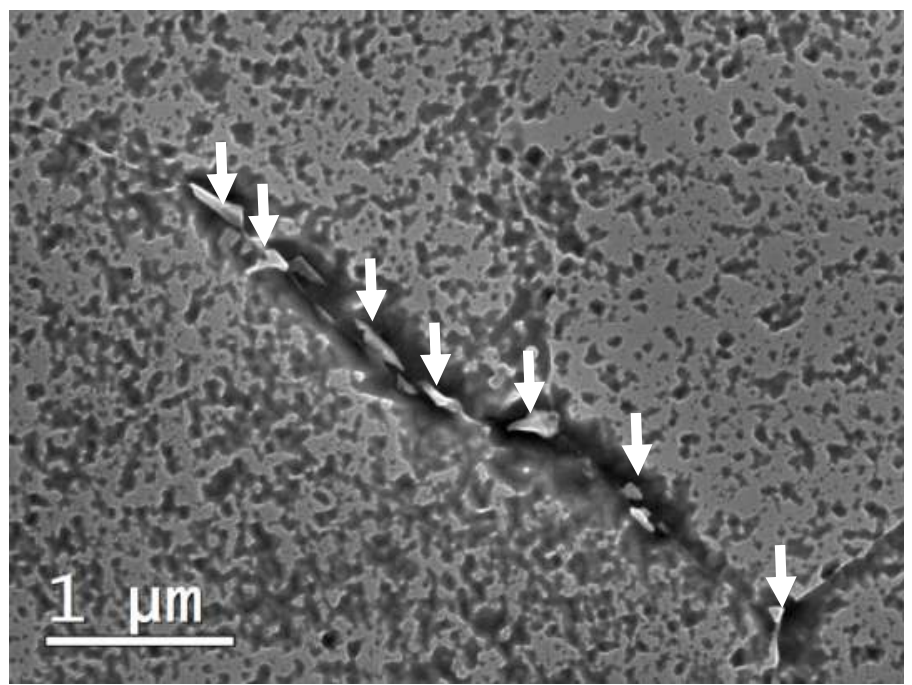

Figure 7. Fine $\mathrm{M}_{23} \mathrm{C}_{6}$ type carbides precipitate along the grain boundary running diagonally. 
and are controversial carbides. Firstly, this is because their different morphologies: the blocky shaped ones at grain boundaries have a beneficial effect on rupture strength; on the contrary the film ones are regarded as promoting early rupture failure [4]. Secondly, this is because that they make a Cr depleted zone (Fig. 9) around the precipitate. In this area, it is difficult to form a protective oxide, namely $\mathrm{Cr}_{2} \mathrm{O}_{3}$, due to lack of $\mathrm{Cr}$.
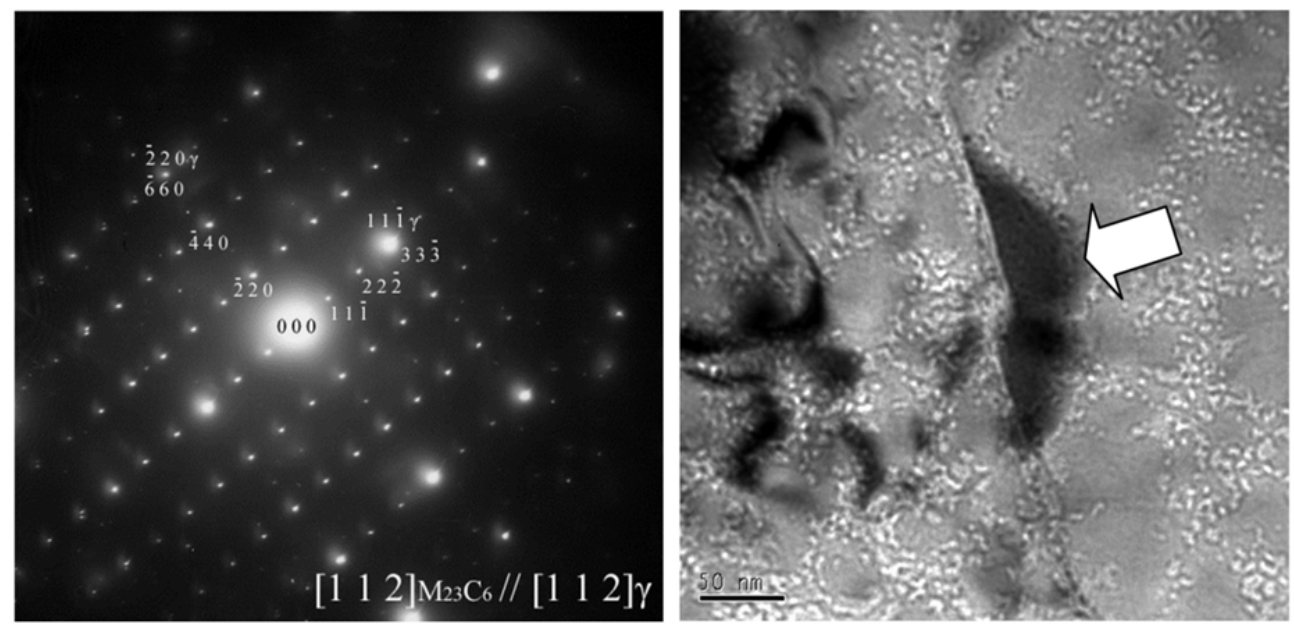

Figure 8. $\mathrm{M}_{23} \mathrm{C}_{6}$ and $\gamma$ matrix perfect coherent diffraction pattern (left) and the bright field image from another beam direction to make $\mathrm{M}_{23} \mathrm{C}_{6}$ outstanding (right)
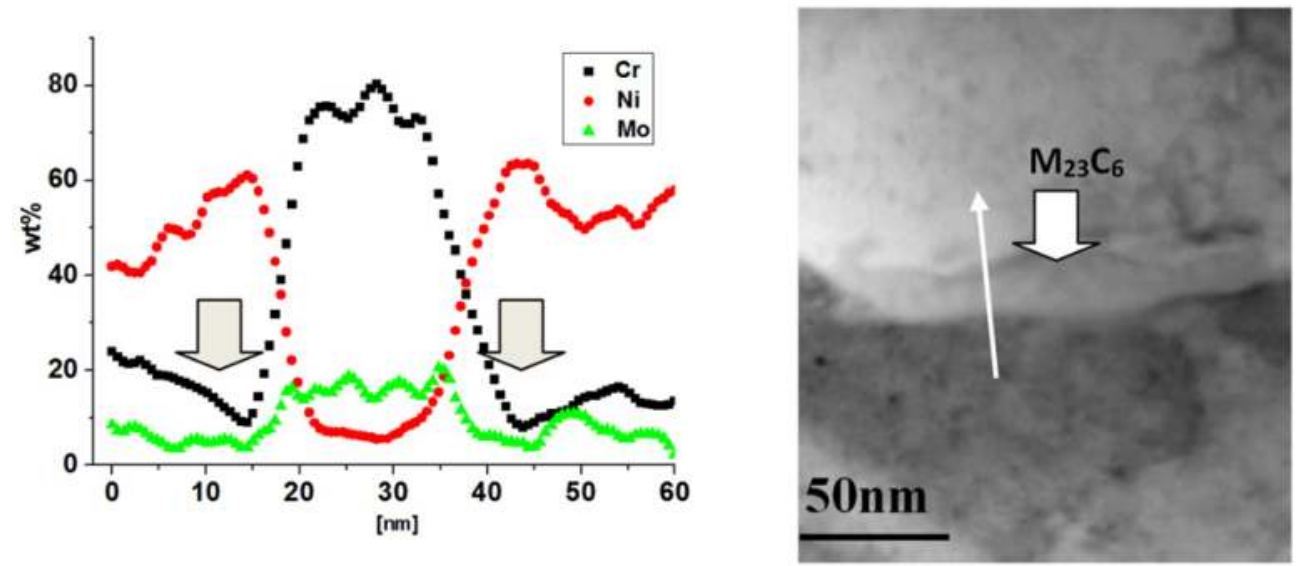

Figure 9. Left: STEM EDX line scan results across $\mathrm{M}_{23} \mathrm{C}_{6}$ revealed the $\mathrm{Cr}$ depletion as indicated by the arrows ( $\mathrm{Cr}$ nominal composition is $15 \mathrm{wt} \%$ ). Right: STEM bright field image of the $\mathrm{M}_{23} \mathrm{C}_{6}$ (the thin arrow shows the length and the direction of the EDX line scan) 
It is broadly acknowledged that boron segregation along the grain boundary increases the cohesive strength of the grain boundaries. The role of borides is, however, still under open discussion. Those so far identified have a base centred tetragonal (BCT), $\mathrm{M}_{3} \mathrm{~B}_{2}$ [4] or $\mathrm{M}_{5} \mathrm{~B}_{3}$ [7] formula, where $\mathrm{M}$ is typically a refractory element, namely Mo or Cr. They appear as various shapes such as blocky to half-moon [4]. The examples shown in Fig. 10 were found in an advanced polycrystalline Ni superalloy after a thermal exposure at $980^{\circ} \mathrm{C}$ for 1 hour.
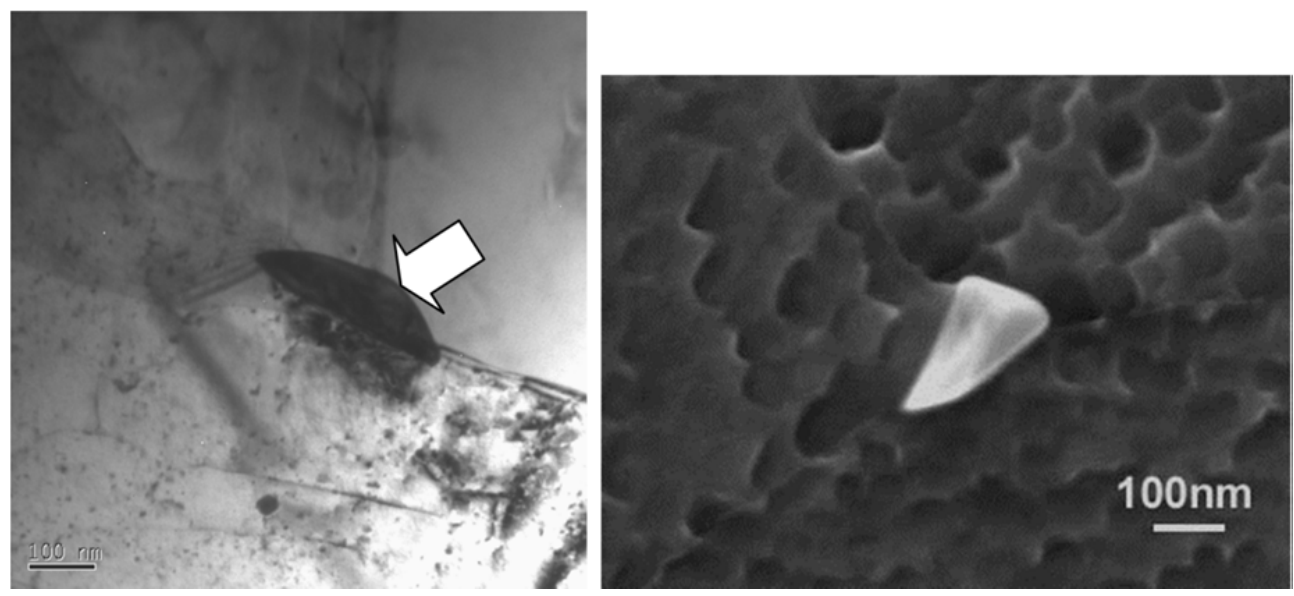

Figure 10. Some examples of $\mathrm{M}_{5} \mathrm{~B}_{3}$ type boride appeared in TEM bright field (left) and in SEM (right)

\subsection{Other phases}

Adding excess quantity of refractory elements, such as Mo, $\mathrm{W}$ and Re, promotes the precipitation of hard intermetallic phases [2], so called TCP phase, which are believed to deteriorate the alloy ductility [4] and the creep life [8]. In the ternary phase diagrams for superalloy elements, such as $\mathrm{Ni}-\mathrm{Cr}-\mathrm{Mo}$, there are two phase spaces: one is austenite $(\gamma) \mathrm{fcc}$ and the other is bcc [4]. Between these two major fields, a band of numerous small phase volumes can be identified such as $\sigma, \mu, \mathrm{R}$ and so on [4], which are characterized firstly as having a high and uniform packing density of atoms[2] and secondly as having complex crystal structures [2], either hcp, body centred tetragonal or rhombohedral. With the careful control of these refractory elements, TCP phases occur after a long time service or a prolonged heat treatment [9]. Some are believed to be the products of transformation from another beneficial phase: for example $\eta\left(\mathrm{Ni}_{3} \mathrm{X}\right)$ results from $\gamma^{\prime}[4]$ and $\sigma$ has the same crystal structure as that of $\mathrm{M}_{23} \mathrm{C}_{6}$, but without the carbon atoms. The example of $\sigma$ phase shown in Fig. 11 was found to be $\mathrm{Cr}$, Mo and Co based chemistry after a thermal exposure at $720^{\circ} \mathrm{C}$ for 1,100 hours in a newly developed advanced $\mathrm{Ni}$ superalloy. The second phases introduced above and some other important second phases for the $\mathrm{Ni}$ superalloy microstructure are summarized in Table 1. 


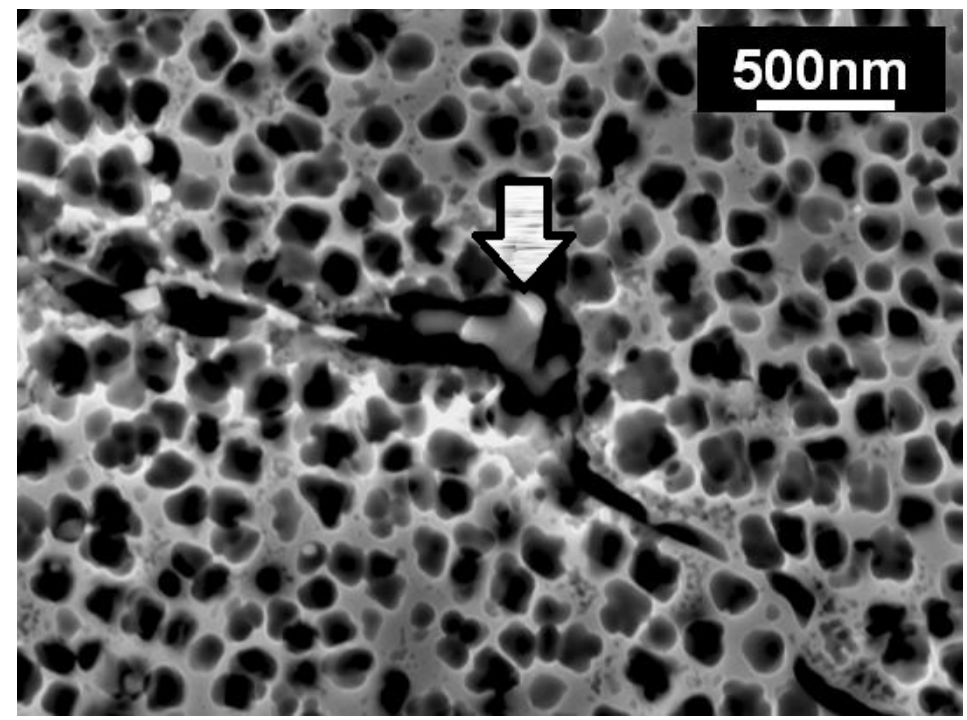

Figure 11. Sigma $(\sigma)$ phase precipitates on the grain boundary running diagonally from top left to bottom right

\begin{tabular}{|c|c|c|c|c|c|}
\hline Phase & Prototype & $\begin{array}{l}\text { Pearson } \\
\text { symbol }\end{array}$ & $\begin{array}{l}\text { Strukturbericht } \\
\text { symbol }\end{array}$ & Lattice [nm] & $\begin{array}{l}\text { Chemical } \\
\text { Composition (Appx) }\end{array}$ \\
\hline$\gamma^{\prime}$ & $\mathrm{Cu}_{3} \mathrm{Au}$ & $\mathrm{cP} 4$ & $\mathrm{~L}_{2}$ & a 0.36 & $(\mathrm{Ni} \mathrm{Co})_{3}(\mathrm{Al} \mathrm{Ti})$ \\
\hline$\gamma^{\prime \prime}$ & $\mathrm{Al}_{3} \mathrm{Ti}$ & $\mathrm{tI} 8$ & $\mathrm{D}_{22}$ & a 0.36 с 0.74 & $(\mathrm{Ni} \mathrm{Fe})_{3}(\mathrm{Nb} \mathrm{Al} \mathrm{Ti})$ \\
\hline $\mathrm{MC}$ & $\mathrm{NaCl}$ & cF8 & B1 & a 0.44 & $\begin{array}{l}\text { (Ti Ta)C or } \mathrm{TiC}, \mathrm{TaC} \\
\mathrm{NbC}, \mathrm{WC}\end{array}$ \\
\hline $\mathrm{M}_{6} \mathrm{C}$ & $\mathrm{Fe}_{3} \mathrm{~W}_{3} \mathrm{C}$ & cF112 & $\mathrm{E}_{3}$ & a 1.11 & $(\mathrm{Mo} \mathrm{Cr} \mathrm{W})_{6} \mathrm{C}$ \\
\hline $\mathrm{M}_{7} \mathrm{C}_{3}$ & $\mathrm{Cr}_{7} \mathrm{C}_{3}$ & oP40 & $\mathrm{D} 10_{1}$ & a 0.45 b 0.70 c 1.21 & $\mathrm{Cr}_{7} \mathrm{C}_{3}$ \\
\hline $\mathrm{M}_{23} \mathrm{C}_{6}$ & $\mathrm{Cr}_{23} \mathrm{C}_{6}$ & cF116 & D8 4 & a 1.07 & $\mathrm{Cr}_{21} \mathrm{Mo}_{2} \mathrm{C}_{6}$ \\
\hline $\mathrm{M}_{5} \mathrm{~B}_{3}$ & $\mathrm{Cr}_{5} \mathrm{~B}_{3}$ & $\mathrm{tI} 32$ & D81 & a 0.55 с 1.06 & $(\mathrm{Cr} \mathrm{Mo})_{5} \mathrm{~B}_{3}$ \\
\hline $\mathrm{M}_{3} \mathrm{~B}_{2}$ & $\mathrm{Si}_{2} \mathrm{U}_{3}$ & $\mathrm{tP} 10$ & D5a & a 0.60 с 0.32 & $(\mathrm{Mo} \mathrm{Cr})_{3} \mathrm{~B}_{2}$ \\
\hline$\sigma$ & $\mathrm{CrNi}$ & tP30 & $\mathrm{D} 8 \mathrm{~b}$ & a 0.88 с 0.46 & Cr Mo Co based \\
\hline$\delta$ & $\mathrm{Cu}_{3} \mathrm{Ti}(\beta)$ & oP8 & D08 & a 0.51 b 0.43 c 0.46 & $\mathrm{Ni} 3 \mathrm{Nb}$ \\
\hline$\eta$ & $\mathrm{Ni} 3 \mathrm{Ti}$ & hP16 & $\mathrm{D}_{24}$ & а 0.51 с 0.83 & $\mathrm{Ni}_{3}(\mathrm{Ti} \mathrm{Ta})$ \\
\hline$\mu$ & $\mathrm{Fe}_{7} \mathrm{~W}_{6}$ & hR13 & $\mathrm{D} 85$ & a 0.48 с 2.5 & Mo Co based \\
\hline
\end{tabular}

Table 1. Summary of second phases in the polycrystalline Ni based superalloys [10] The lattice parameter may vary (less than $5 \%$ ) by changing chemical composition. 


\section{Microstructures and mechanical properties}

It is worth noting the microstructure related mechanical properties in detail. We will discuss briefly how microstructure affects various mechanical properties in polycrystalline $\mathrm{Ni}$ superalloys.

Altering grain sizes results in various effects with regard to the different mechanical properties. Tensile and fatigue life properties are optimized by a fine grain microstructure, on the other hand, good creep and fatigue crack growth properties at elevated temperature are favoured by a coarse grain microstructure [2]. The former is a result of grain orientation and stress concentration by dislocation movement along the slip plane [2]. The latter is about intergranular crack propagation susceptibility. For example, Bain et al [11] showed the significance of the grain size for the crack growth rate using UDIMET720. Testing at $650^{\circ} \mathrm{C}$, the crack growth rate reduced by more than two orders of magnitude by changing the size from 20 to $350 \mu \mathrm{m}$ in diameter. (Fig. 12).

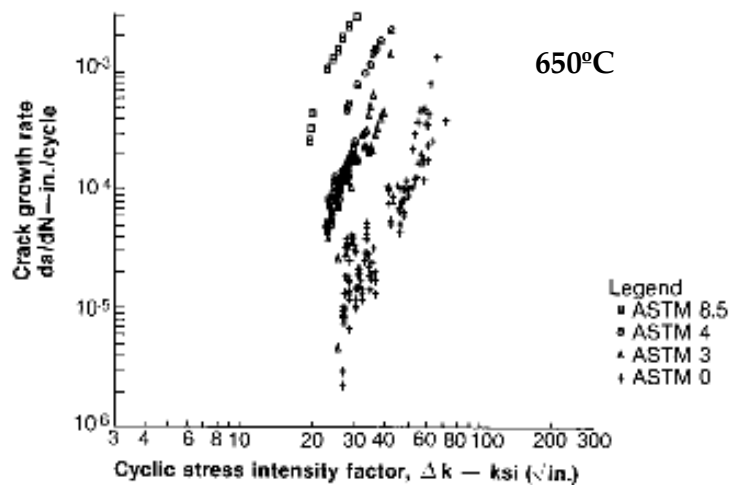

Figure 12. UDIMET 720 fatigue crack growth rate for different grain sizes (ASTM grain size between 0 and 8.5: $360 \mu \mathrm{m}$ and $19 \mu \mathrm{m}$ in diameter) tested at $650^{\circ} \mathrm{C}[11]$

The size of the hardening precipitates significantly affects the yield strength of the material via the interaction between the precipitate and the dislocation. If the precipitates are large, dislocation bowing around the precipitates becomes dominant; for small sized precipitates, dislocation cutting becomes dominant.

For bowing

$$
\tau=\frac{G * b}{L-2 r}
$$

and for cutting

$$
\tau=\frac{r * \gamma * \pi}{b * L}
$$

$\tau$ is the strength of the material, $G$ is the shear modulus, $b$ is the magnitude of the Burgers vector, $L$ is the distance between the hardening precipitates, $r$ is the radius of the precipitates and $\gamma$ is the surface energy. In general in $\mathrm{Ni}-\mathrm{Al}$ binary system, the optimum size to 
maximize the strength is found to be around 5 - $30 \mathrm{~nm}$ in diameter (Fig. 13). The size of the precipitates also affects the creep strain as shown in Fig. 14. In their study [12], the size of the precipitate was changed by changing the heat treatment temperature and time and found that the smaller the precipitate the slower the creep strain rate is, which is achieved via the smaller $\gamma^{\prime}-\gamma^{\prime}$ channel width $[12,13]$.

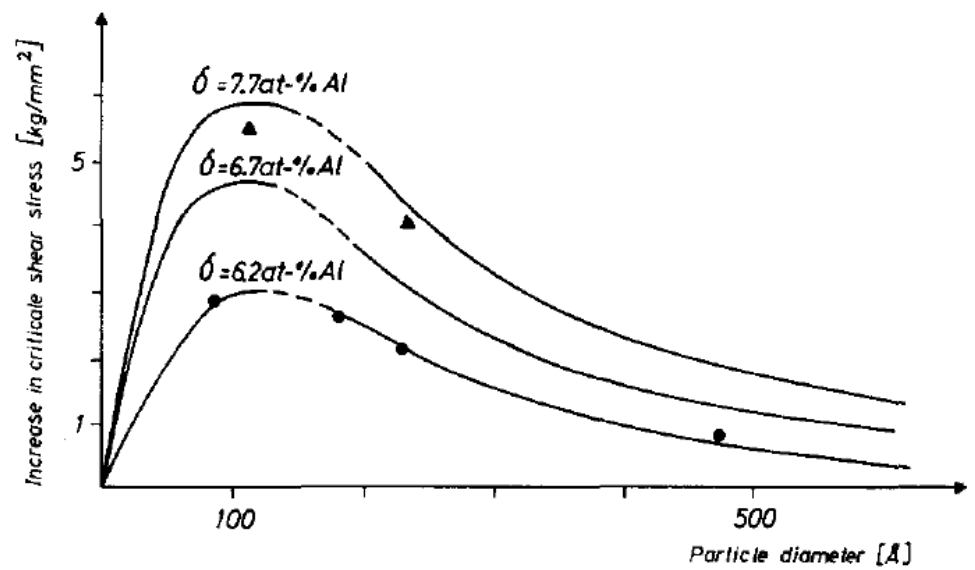

Figure 13. $\gamma^{\prime}$ particle diameter against the critical shear stress in $\mathrm{Ni}-\mathrm{Al}$ system [28]

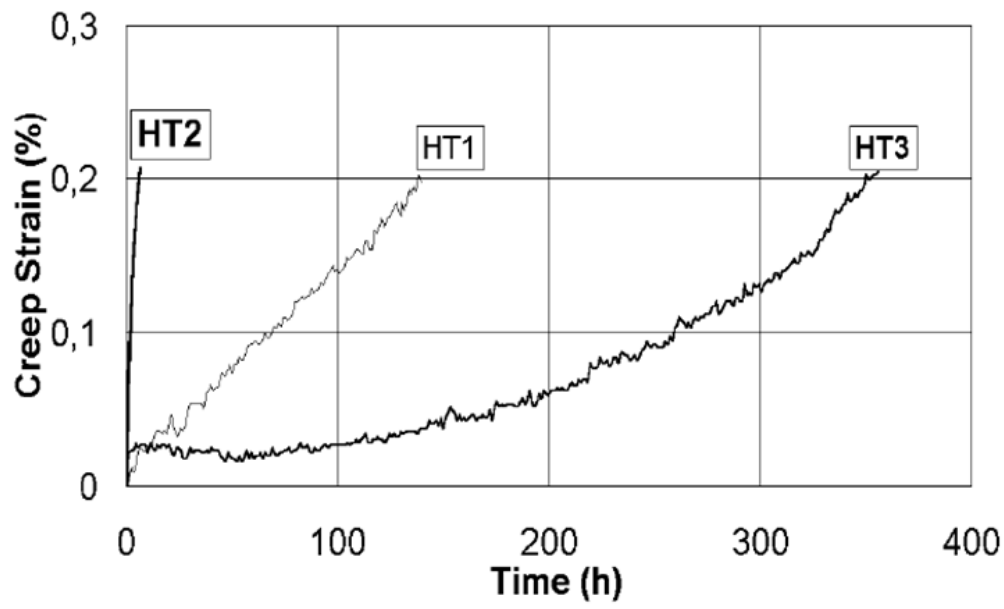

Figure 14. Creep strain tested at $700^{\circ} \mathrm{C}$ for different heat treatments (HT1, HT2 and HT3) The size of $\gamma^{\prime}$ : HT2>HT1>HT3 [12].

It is well known fact that in general both the yield strength and the creep rupture strength increases by increasing the hardening precipitate volume fraction [2]. Historically, low cycle fatigue life was the main concern for turbine disc alloys, but fatigue crack growth rate and damage tolerant design have attracted more attention over the last two decades [11, 14]. 
They can be strongly influenced not only by the size of the grains as introduced above, but also by the size of the precipitates; the striking results were shown in Ref. $[15,16]$. The results show that the larger the hardening precipitates the better the crack growth property. However, this conflicts with the creep life property as mentioned above. Research on damage tolerant design originally started to investigate the grain boundary chemistry since fast crack growth (FCG) is always observed with intergranular cracks and tends to disappear at low temperature. Additionally, transgranular ductile cracking replaces intergranular crack when the tests carried out in the reduced oxygen partial pressure $[17,18]$ (Fig. 15) Thus, FCG embrittlement has been attributed to oxidation [11, 19]. Grain boundary engineering has been explored by changing the morphology of the grain boundary. For example, Ref. $[15,20]$ reported a complex grain boundary geometry, so called 'serrated' (Fig. 16), by slow cooling after solution treatment. The result showed slower intergranular crack growth rate than with a normal grain boundary [15]. However, the improvement above did not account for the property change by the different size of the hardening precipitate mentioned above. The fast intergranular crack growth at high temperature in superalloys added a new dimension after intensive studies with regard to the correlation between the hardening precipitate distribution and the crack growth rate. Ref. [15, 16, 21] claimed that the prevention of stress relaxation of the crack tip by the hardening precipitates can increase the crack growth rate. Some experimental work support the idea, for example Andieu et al [22] carried out a unique dwell fatigue crack propagation test where oxygen was introduced in different phases of the low cycle fatigue crack growth test and found that it is potent for the fast crack growth when oxygen is introduced at the beginning of the loading rather than introducing in the later part of the loading. This may imply that the oxidation at the crack tip happens during the stress concentrated at the crack tip. Molins et al [23, 24] concluded that the local microstructure at the crack tip, which can be controlled by an appropriate heat treatment against the stress accumulation, can significantly affect the crack propagation behaviour in $\mathrm{Ni}$ superalloys. This conclusion recalls an arguable grain boundary microstructure feature, namely the precipitate free zone (PFZ). One suggested that the PFZ would promote plastic deformation and fracture [25,26]. Another suggested that the PFZ in some nickel alloys is beneficial for crack tip stress relaxation [27].

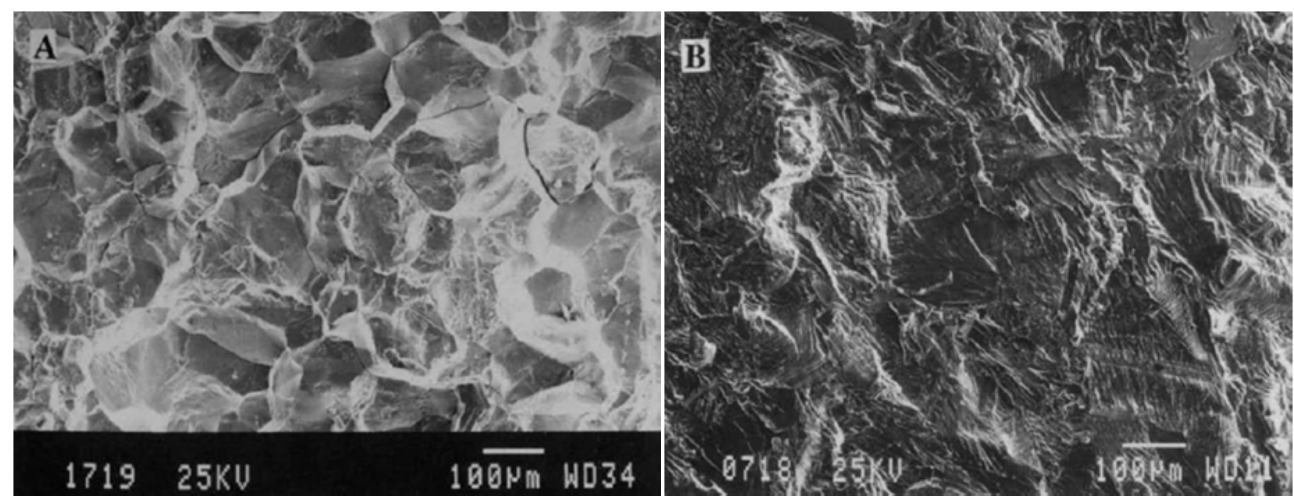

Figure 15. Typical intergranular (left) and transgranular (right) fracture surfaces. Alloy 718 tested at $650^{\circ} \mathrm{C}$ in air (left) and vacuum (right) [18] 
These findings above suggest that not only the macroscopic structure such as the grain size and the distribution of the hardening precipitates, but also the microscopic structure, such as the grain boundary shape and the relationship with the hardening precipitates, can significantly affect the mechanical properties.

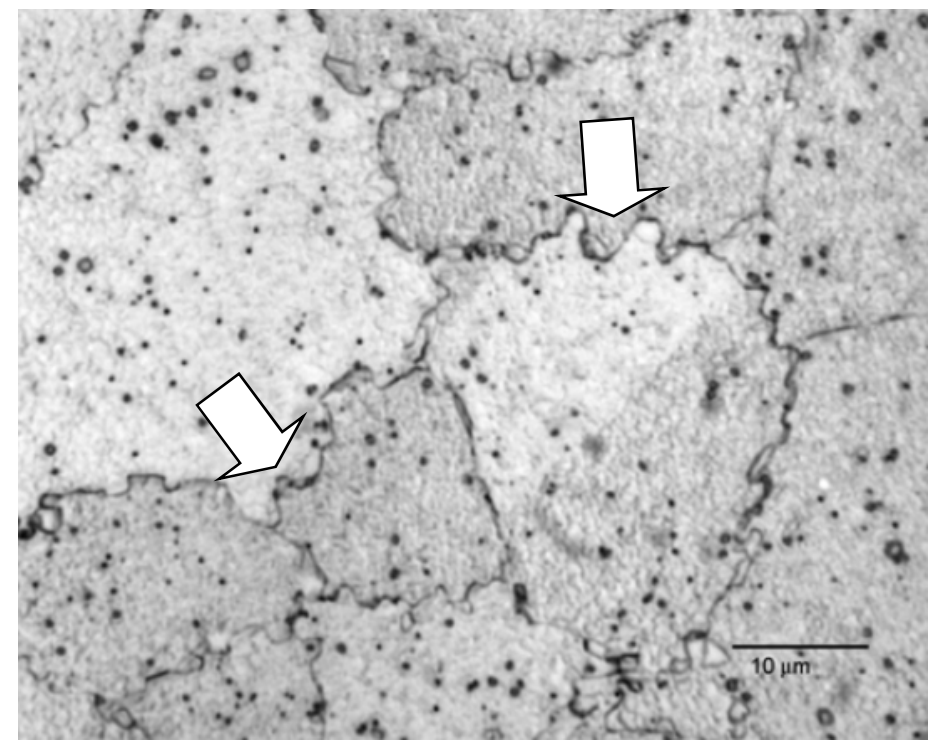

Figure 16. Optical microscopy image of serrated grain boundaries. The arrows indicate the serrated boundaries [15]

\section{Polycrystalline superalloy grain boundary structure}

The details of the Ni superalloy grain boundary microstructure will be demonstrated in this section. Particular attention will be paid to the relationship between the hardening precipitates and the high grain boundaries. Fig. 17 shows the STEM bright field image of the grain boundary and the hardening precipitate morphology in an advanced polycrystalline superalloy. The grain boundary running top left to bottom right cuts through $\gamma^{\prime}$. This was confirmed by the conventional TEM image analysis combining with the crystallographic analysis that the either side of the $\gamma^{\prime}$ keeps the coherency with the matrix (Fig. 18). With respect to the morphologies of $\gamma^{\prime}$ on the grain boundaries, it is the same as those inside the grains. It has, however, two different crystallographic orientations keeping the coherency with the either side of the matrix. This morphology is believed to form during the process with the high boundary mobility [29]. There are at least four different possibilities of interactions between the migrating grain boundaries and the precipitates, which are illustrated in Fig. 19. Following Fig. 19,

a. the boundary migrates with no effect on the precipitates; the precipitates thus become incoherent after the migrating grain boundary passes through them. 
b. the precipitates dissolve in contact with migrating boundary and reprecipitate coherently within the new grain.

c. the grain boundary is held by the coherent precipitates which then coarsen, leading to complete halting of the boundary movement.

d. the grain boundary can pass through the coherent precipitate which undergoes the same orientation change as the grain surrounding it and thereby retains the coherent low-energy interface between the precipitate and the matrix.

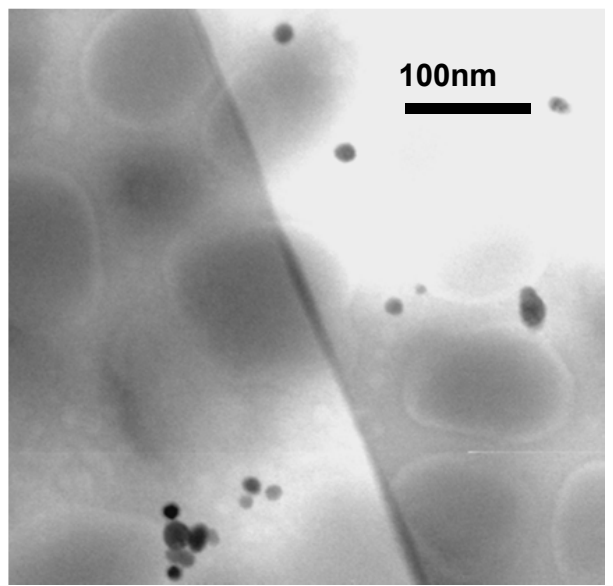

Figure 17. General aspect of the high angle grain boundary and $\gamma^{\prime}$ (dark spheres). The grain boundary is running diagonally from top left to bottom right
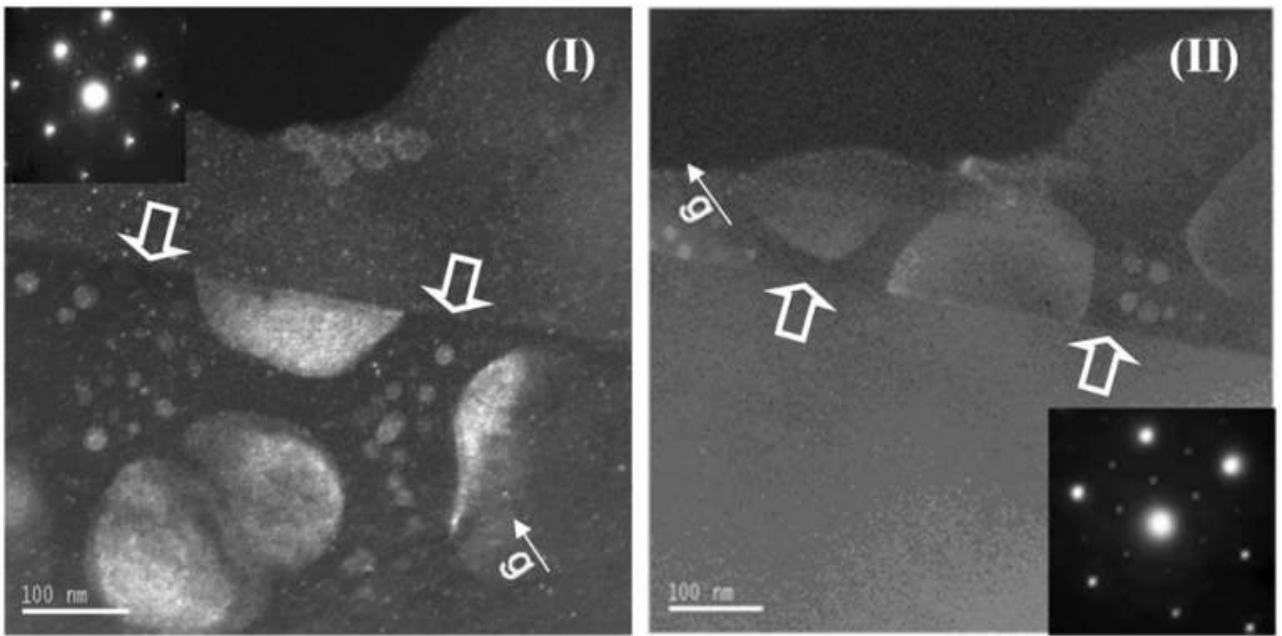

Figure 18. A crystallographic analysis of the cutting $\gamma^{\prime}$. The dark field images of the lower and the upper grain are in (I) and (II), respectively. The white arrows indicate the grain boundary 
With regard to theory a), this is often observed with high solvus temperature precipitates, such as carbides and oxides. b) is not applicable in this study. This can be, however, the case for less $\gamma^{\prime}$ volume fraction superalloys with small amount of nominal Al content such as Nimonic PE16 or the case in high temperature very close to the $\gamma^{\prime}$ solvus. With regard to c), it can be applicable in the case of the larger $\gamma^{\prime}$ such as the one in Fig. 4. d) is relevant to explain the results of Fig. 17 and Fig. 18. As the grain boundary impinges on the $\gamma^{\prime}$, the grain boundary apparently cuts off $\gamma^{\prime}$. Firstly, the interface free energy between $\gamma^{\prime}$ and the grain boundary increases. This results in dissolving the $\gamma^{\prime}$ at the interface but due to the supersaturation of $\gamma^{\prime}$ formers, such as $\mathrm{Al}$ and $\mathrm{Ti}, \gamma^{\prime}$ immediately re - nucleates in the next grain coherent with the next grain discontinuously [30,31]. Thus, this phenomenon can be concluded the result of $\gamma^{\prime}$ dissolution and subsequent (discontinuous) precipitation.
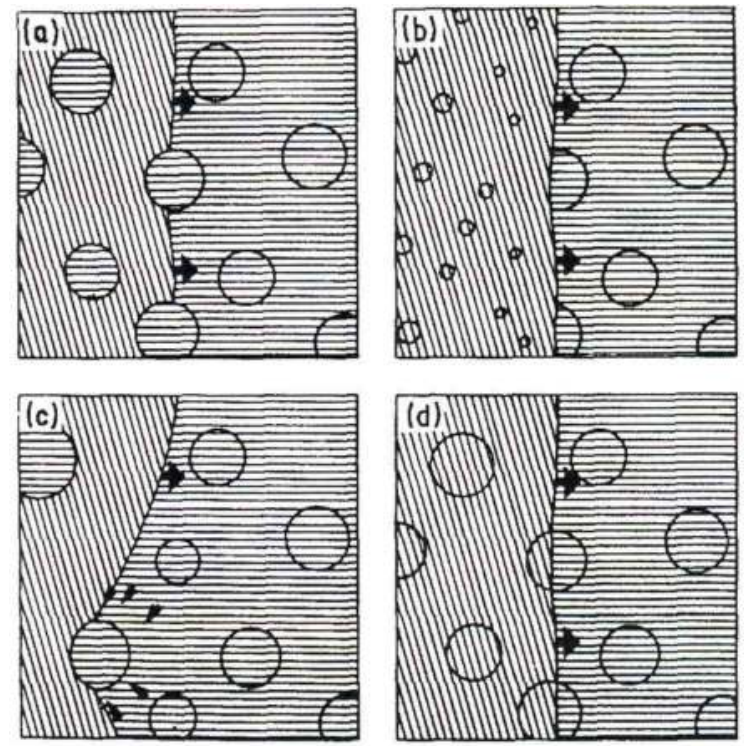

Figure 19. The possible interactions between the migrating grain boundary and the precipitate [29]

Another example is forming a precipitate free zone (PFZ) as shown in Fig. 20 in IN718. $\gamma^{\prime}$ and $\gamma^{\prime \prime}$ coexist in IN718, however, $\gamma^{\prime \prime}$ denude along the grain boundary and form a $\gamma^{\prime \prime}$ PFZ. On the contrary, the minor hardening precipitate in IN718: $\gamma^{\prime}$ exist along the grain boundary. Vacancy deficiency is one of the causes of the PFZ along grain boundaries due to lack of the nucleation sites as grain boundary acts as a good vacancy sink [32]. One of the important factors to create the PFZ in the superalloys can be the difference of the interfacial free energy, i.e. the free energy between $\gamma^{\prime}$-matrix and $\gamma^{\prime \prime}$-matrix. The $\gamma^{\prime \prime}-\gamma^{\prime \prime}$ nucleus channel distance along the grain boundary can be larger than the critical distance to aggregate two $\gamma^{\prime \prime}$ nuclei. On the other hand, the critical distance for the $\gamma^{\prime}$ is smaller than that of $\gamma^{\prime \prime}$ or $\gamma^{\prime}$ can nucleate their precipitate independently as $\gamma^{\prime}$ has smaller interfacial energy. Thus, the $\gamma^{\prime}$ nuclei can grow and form precipitates along the grain boundary but not for $\gamma^{\prime \prime}$ and the $\gamma^{\prime \prime}$ PFZ arises. 


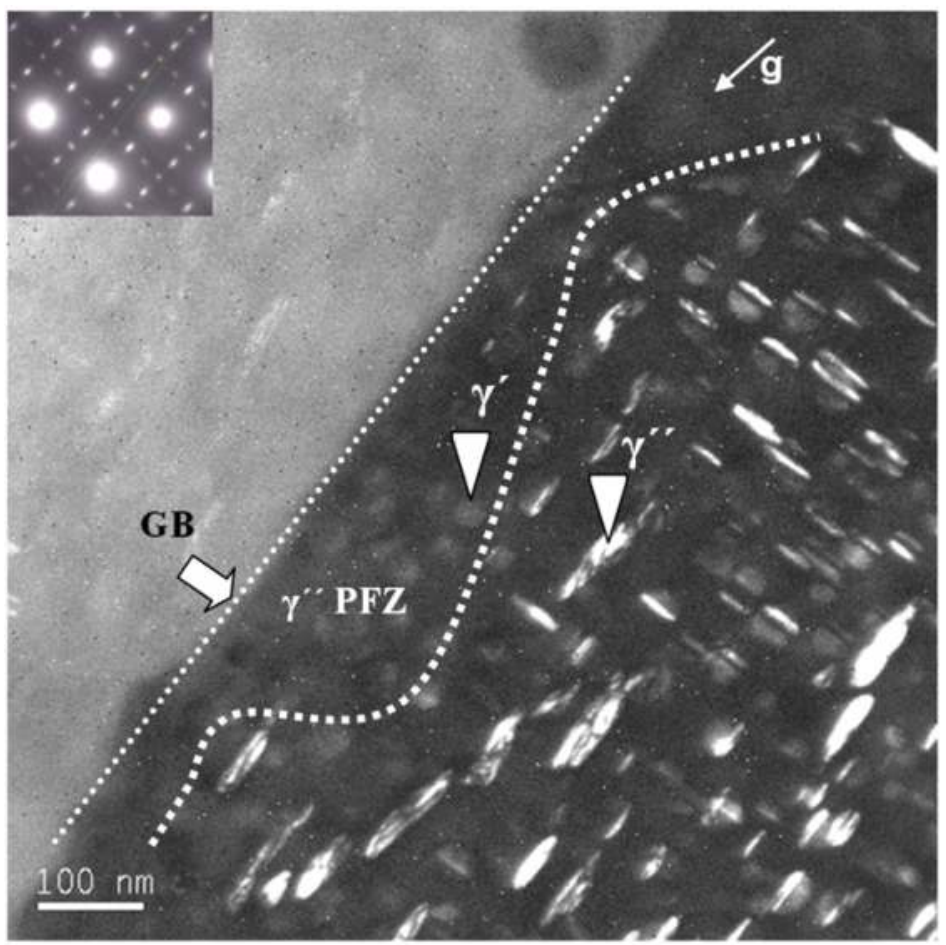

Figure 20. $\gamma^{\prime \prime}$ PFZ appeared in IN718, although $\gamma^{\prime}$ still exist in the $\gamma^{\prime \prime}$ PFZ adjacent to the grain boundary

\section{High temperature oxidation along grain boundaries}

The context of 'High temperature' in this section is the temperature range of $600-700^{\circ} \mathrm{C}$ which is the high temperature regime of the disc in the turbine engine application.

It is more than a half century ago, the investigation of the oxidation assisted fast crack growth started. $\mathrm{Cr}$ is believed to be an important element for the oxidation assisted crack growth. For example, as shown in Fig. 21, crack growth tests were conducted under various oxygen partial pressure on Ni-Cr binary alloys with 5, 20 and $30 \mathrm{wt} \%$ of $\mathrm{Cr}$. It was found that the higher the $\mathrm{Cr}$ content the higher the transition oxygen partial pressure from transgranular to intergranular cracking is. The highest $\mathrm{Cr}$ content alloy: $\mathrm{Ni}-30 \mathrm{wt} \% \mathrm{Cr}$ did not show a transition pressure. Oxidation process on a freshly exposed alloy surface had been characterised intensively and well understood. As illustrated in Fig. 22, both $\mathrm{Ni}$ and $\mathrm{Cr}$ oxide formation takes place at the beginning of the oxidation [33]. This is particularly important for alloys on the borderline between protective and non-protective behaviour [34]. But in the early stage, the fast kinetics $\mathrm{Ni}$ oxide grows quickly and dominates the oxide. In general, there are two types of oxidation: the cation diffusion type and the anion diffusion type [34]. The difference between the two is the movement of the ions; the former involves cation (metal ion) transport, the latter anion (oxygen ion) transport. For the cation diffusion type the oxides form between the oxide and the free surface, but, for the anion diffusion, the oxides form between the oxide and the metal 
interface. During the transient stage which corresponds to the middle of the illustrations in Fig. 22, $\mathrm{Cr}_{2} \mathrm{O}_{3}$ particles are embedded inside the $\mathrm{NiO}$ layer. As $\mathrm{NiO}$ grows and the oxidation rate becomes slower, $\mathrm{Cr}_{2} \mathrm{O}_{3}$ soon establishes its own layer underneath the $\mathrm{NiO}$ layer, which implies that $\mathrm{Cr}_{2} \mathrm{O}_{3}$ can be the anion diffusion. Eventually the $\mathrm{Cr}_{2} \mathrm{O}_{3}$ layer is completed, where the layer prevents further diffusion of oxygen into the alloy, called passivation [34].

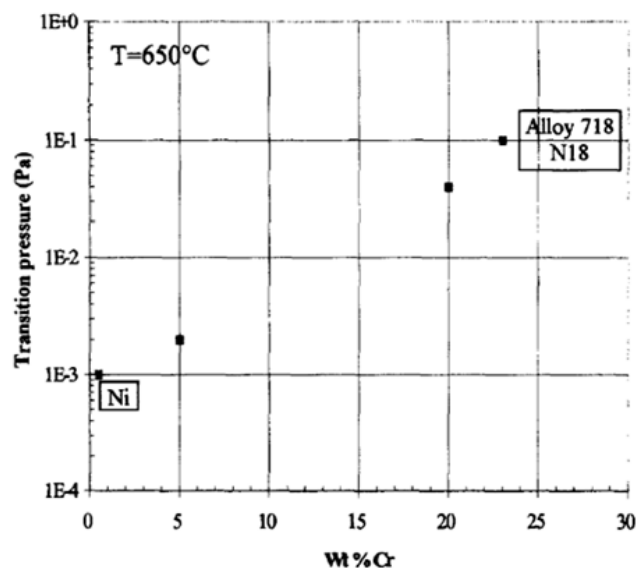

Figure 21. Transition oxygen partial pressure from the transgranular to intergranular cracking against the $\mathrm{Cr}$ concentration in $\mathrm{Ni}$ alloys after crack propagation tests at $650^{\circ} \mathrm{C}$ [24]
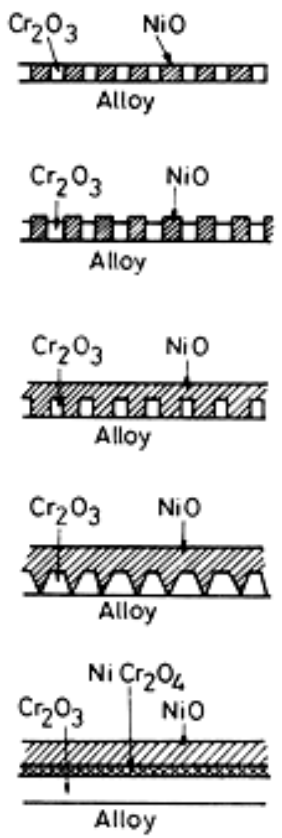

Figure 22. Schematic diagram of the oxidation process (from top to bottom) of the freshly exposed $\mathrm{Ni}$ alloy [33] 
Nevertheless, the oxidation process at (ahead) of the crack tip has remained under debate. This is due to the technical difficulties of studying the microstructure of such small regions, which is predictable taking consideration of the size of the crack tip: less than a micron and even smaller for the oxides adjacent. To overcome the problem, so called 'site specific specimen preparation' has been developed since the late 90's using focused ion beam (FIB) technique [35, 36]. The use of gallium ions in a focused ion beam accelerated in a FIB apparatus to energies up to $30 \mathrm{keV}$ enables us to mill specimens selectively to reveal structural features and to deposit films at selected locations. An example carried out in the University of Birmingham UK (2009) is shown in Fig. 23. The specimen is an advanced Ni based superalloy after an interrupted crack propagation test at $650^{\circ} \mathrm{C}$ in air. A plan-view crack tip TEM specimen was prepared [37]. Using the two different modes: the tungsten deposition to protect the region of interest (Fig. 23 a)) and the milling (trenching) (Fig. 23 b)), the crack tip was transported to a TEM copper grid (c) and d)). The size of the focused Ga ion beam can be achieved as small as a few nanometres in radius. It is possible to prepare the site specific TEM specimen foil as thin as $50 \mathrm{~nm}$ in thickness.

Fig. 24 shows TEM bright field images; they are from the same material: polycrystalline advanced superalloy, but they are after different testing conditions. Fig. 24 (a) is from a specimen after interrupting a crack propagation test at $650^{\circ} \mathrm{C}$; the intergranular crack propagation was identified. Fig. 24 (b) is from a specimen after interrupting the same crack propagation test mentioned above except for the crack growth rate: $0 \mu \mathrm{m} / \mathrm{s}(\sim 0.9 \mathrm{~K}$ th: just below the crack growth threshold) held for 5 hours. The oxides ahead of the crack tip are also along grain boundaries. The dashed line boxes indicate the area analysed by EDX shown later in this section. Comparing the two bright field images in Fig. 24, it is apparent that the oxides penetration in the metal ahead of the crack tip is approximately 5 times longer for the static crack specimen (b).

The EDX mapping and the EDX line scan of the oxides close to the crack tip for the moving crack specimen from the region I in Fig. 24 are shown in Fig. 25. It is apparent that the grain boundary is completely filled with oxides (oxygen map). There is a Co and $\mathrm{Ni}$ rich oxide in the middle. There are $\mathrm{Cr}$ rich oxide areas on both sides of the oxide. $\mathrm{Cr}$ thus forms a thin layer between the $\mathrm{Ni}(\mathrm{Co})$ oxides and the alloy. EDX line scans across the oxide revealed that $\mathrm{Ti}, \mathrm{Al}$ are also segregating in this region. Crystallographic analysis using selected aperture diffraction confirmed that the middle oxide is cubic $\left(\mathrm{Ni}_{x} \mathrm{Co} 1-\mathrm{x}\right) \mathrm{O}$ and the rim oxide is hcp $(\mathrm{Cr}$ $\mathrm{Al} \mathrm{Ti})_{2} \mathrm{O}_{3}$. The higher oxygen partial pressure region in the middle of the oxide is consisted by the $\mathrm{Ni}$ and $\mathrm{Co}$ oxide. The rim of the oxide between the $\mathrm{Ni}(\mathrm{Co})$ oxide and the matrix are consisted by the passive $\mathrm{Cr}, \mathrm{Al}$ and $\mathrm{Ti}$ layer. This is correlating with the freshly exposed $\mathrm{Ni}$ alloy oxidation process described above. Fig. 26 shows the oxide chemistry at the tip of the oxide corresponding to the region II in Fig. 24. According to the EDX mapping, the oxides formation manner looks similar to that of the region $\mathrm{I}$; $\mathrm{Ni}(\mathrm{Co})$ oxide in the middle and the $\mathrm{Cr}$, $\mathrm{Al}$ and $\mathrm{Ti}$ oxide in the rim. It is questionable to argue the stoichiometry of the oxide from the results of the EDX cross section line scan due to the x-ray emission from the matrix, however it revealed from the line scan in Fig. 26 that the oxide is $\mathrm{Cr}$ based; $\mathrm{Ni}, \mathrm{Co}, \mathrm{Al}$ and Ti deplete in the very tip of the oxide. Fig. 27 shows the chemistry of the oxides in the middle of the oxide ahead of the crack tip for the static crack corresponding to the region $\mathbf{x}$ in Fig. 24. EDX mapping revealed that the $\mathrm{Ni}$ and $\mathrm{Co}$ are depleted even in the middle of the oxide and the 

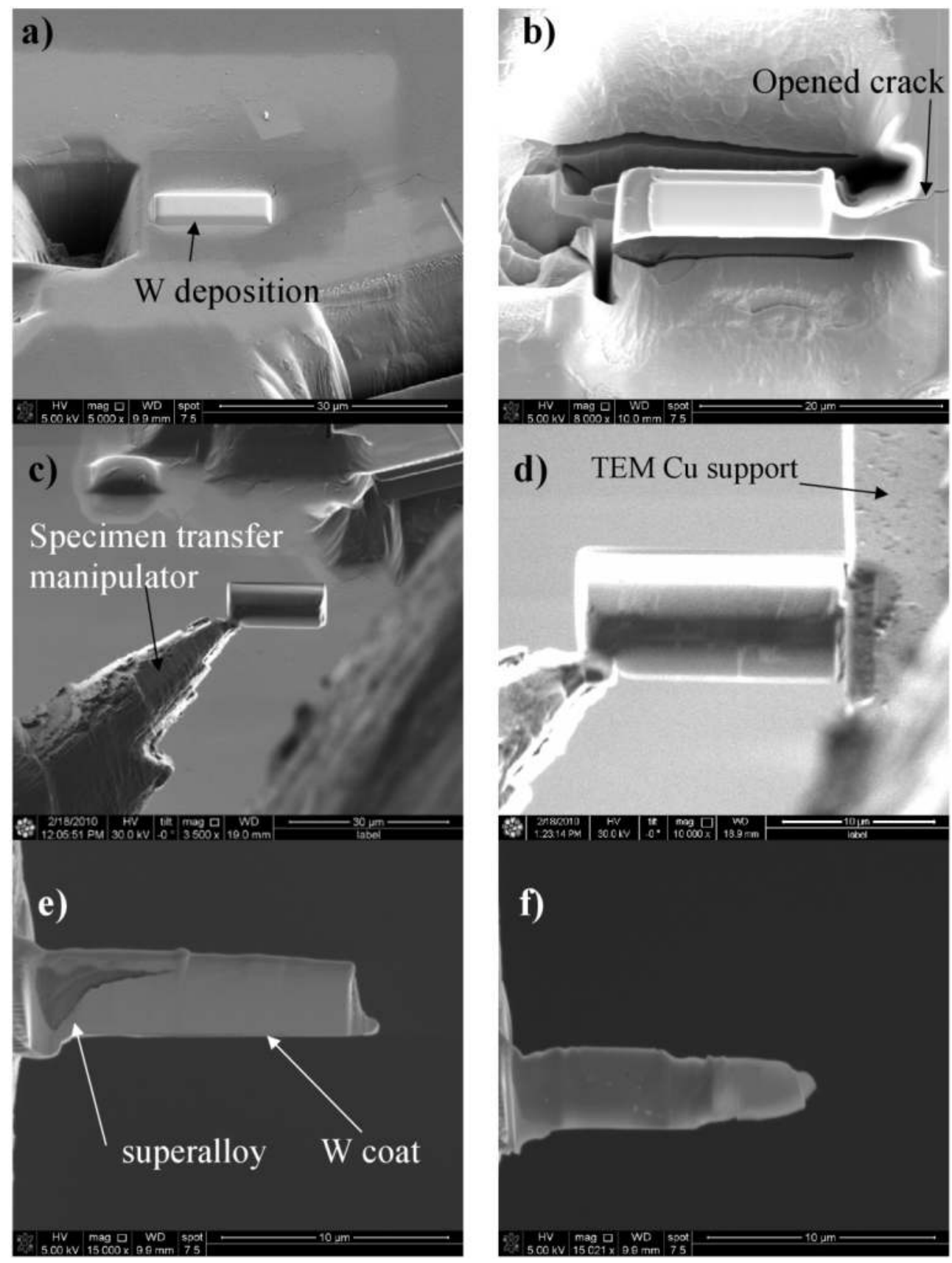

Figure 23. SEM secondary electron images of the process of the site specific TEM sample preparation 

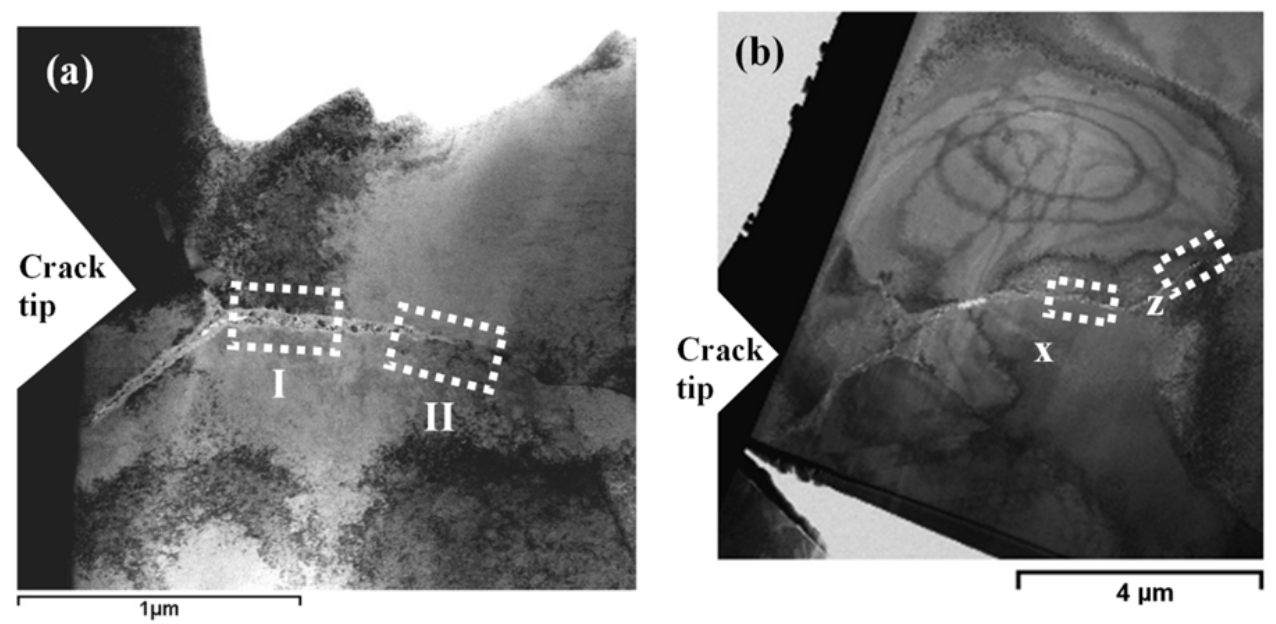

Figure 24. TEM bright field images of the two specimens. The crack tips locate just next to the specimen and the crack propagate from the left to right.
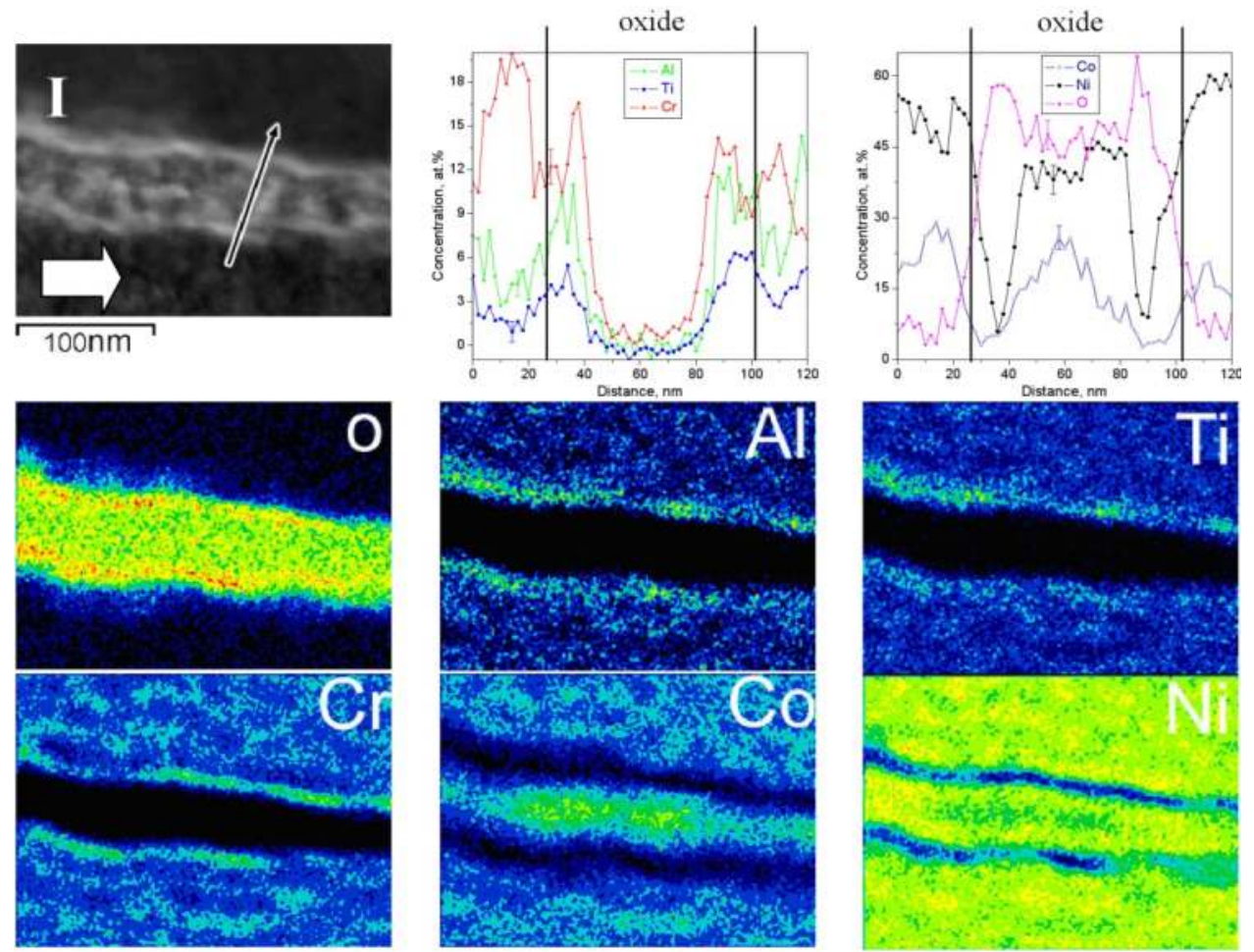

Figure 25. STEM dark field image from the region I in Fig. 24 (top left); the thick white arrow indicates the crack growth direction and the thin black arrow indicates the area and the direction of the EDX line scan. The EDX line scan across the oxide (top right) and the EDX mapping results of the oxide (bottom). 

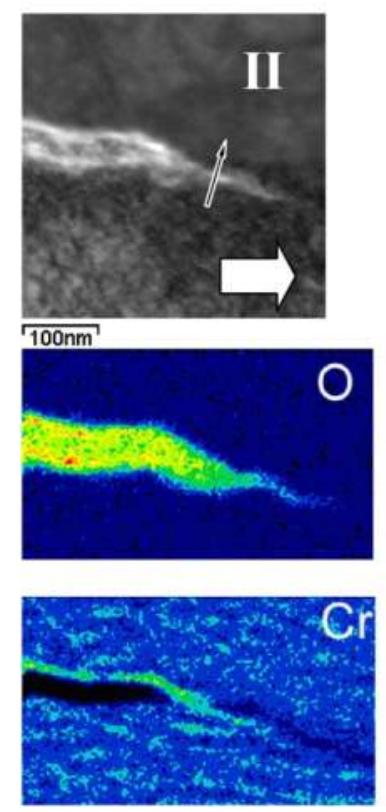
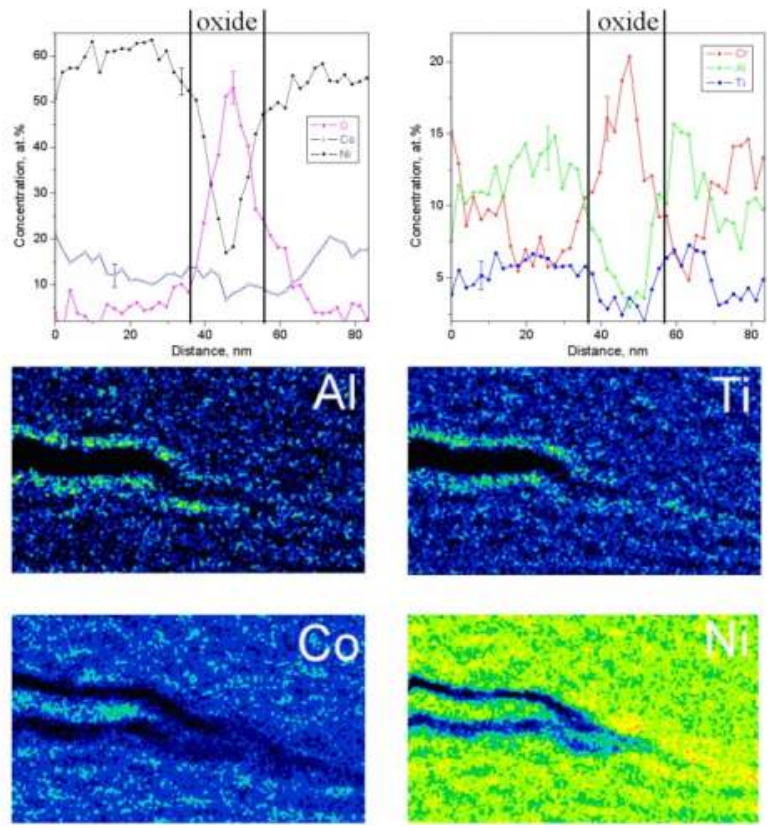

Figure 26. STEM dark field image from the region II in Fig. 24 (top left). The EDX line scan across the oxide (top right) and the EDX mapping results of the oxide (bottom).
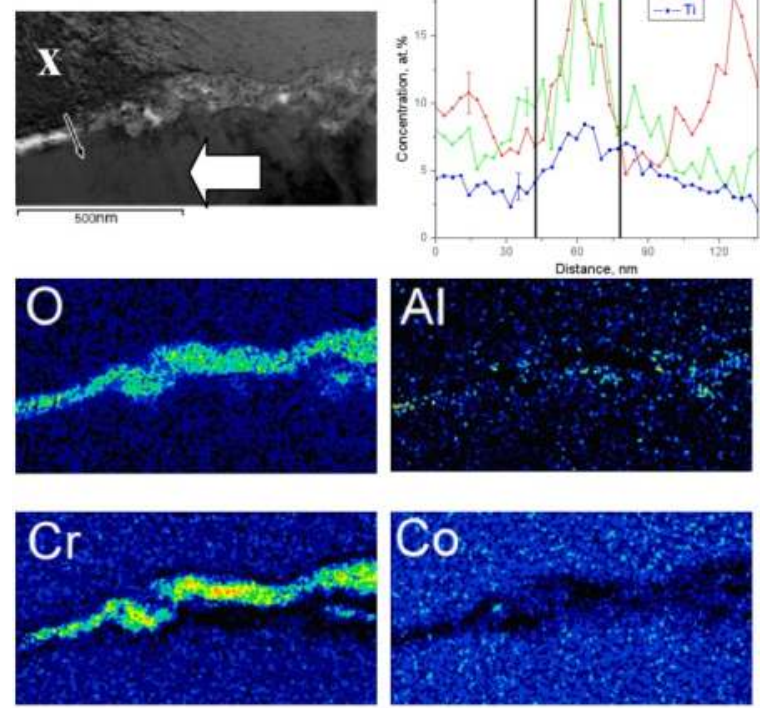
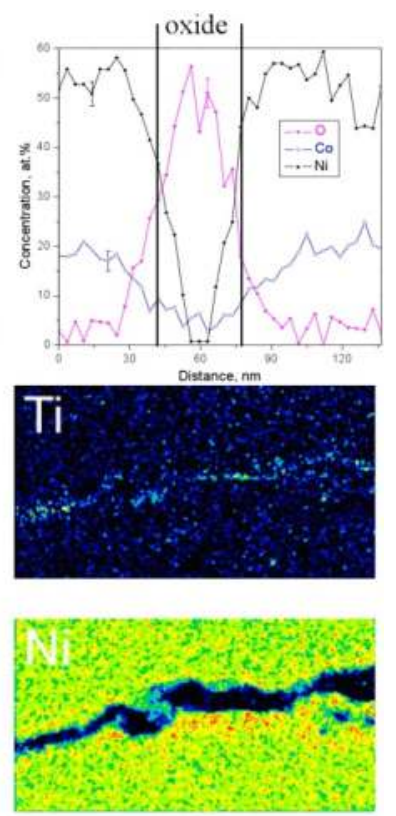

Figure 27. STEM dark field image from the region $x$ in Fig. 24 (top left). The EDX line scan across the oxide (top right) and the EDX mapping results of the oxide (bottom). 
line scan revealed that the oxide is consisted mainly by $\mathrm{Cr}$, Al. Fig. 28 shows the tip of the oxide for the static crack corresponding to the region $\mathbf{z}$ in Fig. 24. Cr still exists in the oxide in the middle, but particularly at the very tip of the oxide approximately $100 \mathrm{~nm}$ or so, $\mathrm{Cr}$ is depleted and only $\mathrm{Al}$ and $\mathrm{Ti}$ enriched at the tip of the oxide (see also the cross section line scan). It is also difficult in this case due to the thickness effect to discuss the stoichiometry of the oxide, however, in this region, $\mathrm{Al}$ and Ti based oxide formation takes place.
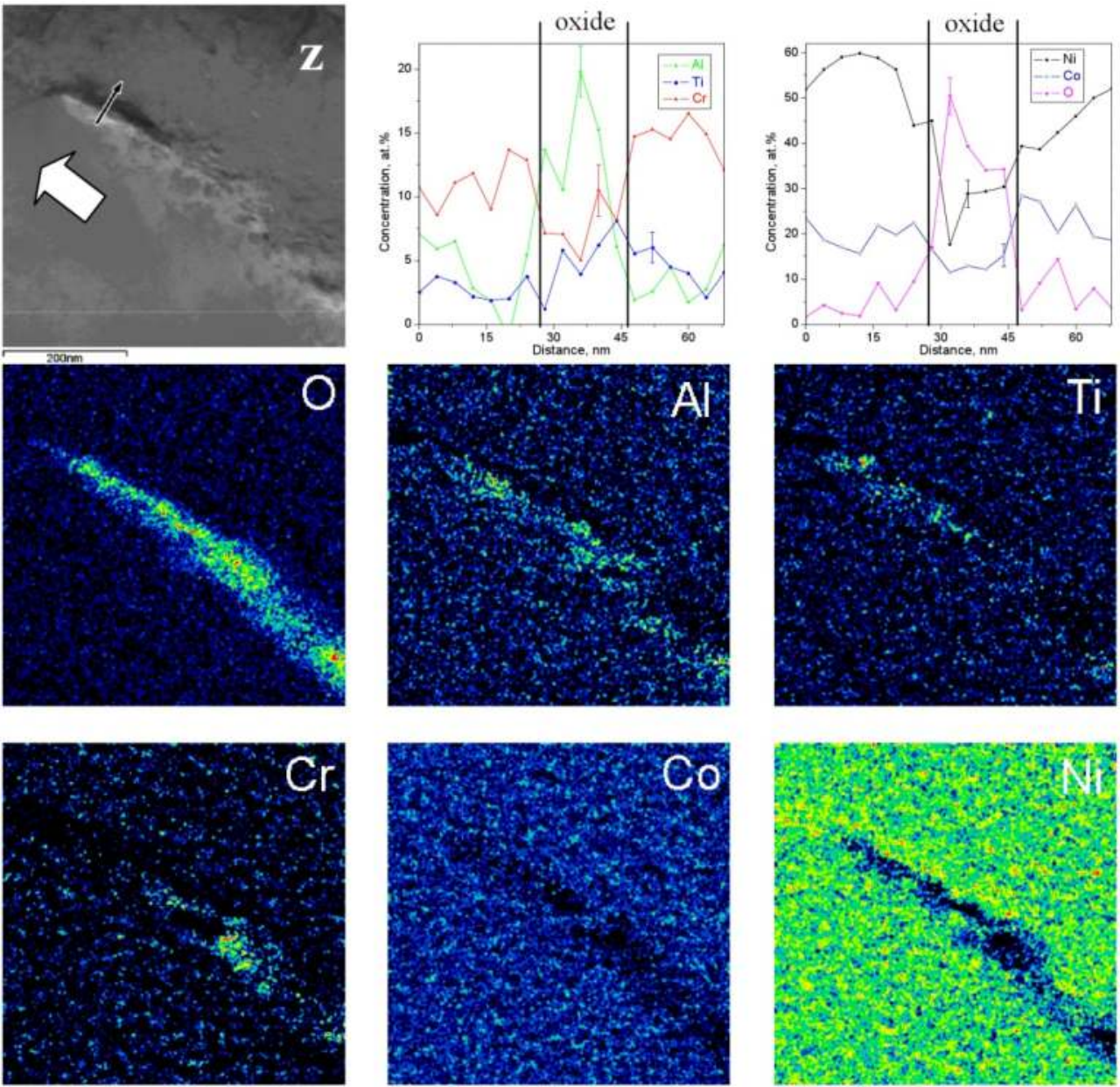

Figure 28. STEM dark field image from the region $\mathrm{z}$ in Fig. 24 (top left). The EDX line scan across the oxide(top right) and the EDX mapping results of the oxide (bottom).

Table 2 shows the oxygen dissociation pressure to form the oxide and the free energy for the elements forming oxides introduced above. It is clear that the formation of the oxide at the crack tip follows the thermodynamics suggesting the oxygen partial pressure gradient along the oxide tip ahead of the crack tip. 


\begin{tabular}{c|ccc}
\hline & Oxide formation & $\begin{array}{r}\text { Free energy } \\
{[\mathrm{kJ} / \text { mole }]}\end{array}$ & $\begin{array}{c}\text { Oxygen dissociation pressure in } \log _{10} \\
{[\text { bar] }}\end{array}$ \\
\hline \hline $\mathrm{Al}$ & $\mathrm{Al} 2 \mathrm{O} 3$ & -1425 & -48 \\
$\mathrm{Ti}$ & $\mathrm{Ti2O}$ & -1295 & -44 \\
& $\mathrm{TiO} 2$ & -798 & -40 \\
$\mathrm{Cr}$ & $\mathrm{Cr} 2 \mathrm{O} 3$ & -877 & -31 \\
$\mathrm{Co}$ & $\mathrm{CoO}$ & -166 & -18 \\
$\mathrm{Ni}$ & $\mathrm{NiO}$ & -149 & -16 \\
\hline
\end{tabular}

Table 2. Oxide formation free energy and the dissociation pressure at $727^{\circ} \mathrm{C}$ for the elements introduced in this section [38]

\section{Summary}

One of the challenges of the advanced $\mathrm{Ni}$ based superalloys is in the damage tolerance properties without reducing their superior strength at high temperature. The microstructure, particularly the grain boundaries, was found to be controlled by the two factors in this study. Firstly, it is the nominal chemical composition, especially the hardening precipitate participants. Secondly, heat treatment has a profound influence of microstructure.

The damage tolerance properties are also concerned with the environmentally assisted crack propagation along grain boundaries, which is essentially the oxidation assisted crack propagation in this study. In general, chromium oxide $\left(\mathrm{Cr}_{2} \mathrm{O}_{3}\right)$ has been regarded as a healing agent of the oxidation process in $\mathrm{Ni}$ alloys. The state-of-the-art technique enabled us to observe the crack tip oxidation. In this study, it was successfully presented that the oxidation sequence is following the free energies for the oxides to form. Thus, for example, $\mathrm{Cr}_{2} \mathrm{O}_{3}$ is one of the earliest oxides to form at the crack tip.

Understanding the environmentally assisted crack propagation is one of the crucial fields of research to increase the turbine entry temperature (TET), which is indeed one of the most significant attainments in the propulsion industries.

\section{Author details}

Hiroto Kitaguchi

Department of Materials, University of Oxford, OX1 3PH, Oxford, UK

\section{Acknowledgement}

The author would thank to Profs. I.P. Jones and P. Bowen at The University of Birmingham and Dr. M.C. Hardy at Rolls-Royce plc for their advice and the guidance. The joint support of the UK Engineering and Physical Sciences Research Council (EPSRC) and Rolls-Royce plc is also gratefully acknowledged. Many thanks are also due to Dr H.Y. Li, Research Fellow at the School of Metallurgy and Materials, The University of Birmingham and Dr Y.Y. Tse, former Research Fellow at the School of Metallurgy and Materials, The University of 
Birmingham, currently Lecturer at Loughborough University, for their assistance with the mechanical tests and the FIB TEM sample preparation.

\section{References}

[1] G.W. Meetham, The Development of Gas Turbine Materials 1st ed., Applied Science, London, 1981.

[2] R.C. Reed, The Superalloys, Cambridge University Press, Cambridge, 2006.

[3] H. Cohen, G.F.C. Rodgers, H.I.H. Saravanamuttoo, Gas turbine theory. Third edition, 1987.

[4] C.T. Sims and W.C. Hagel, The Superalloys, John Wiley and Sons Inc., Canada, 1972.

[5] L.R. Liu, T. Jin, N.R. Zhao, X.F. Sun, H.R. Guan, Z.Q. Hu, Materials Science and Engineering A (Structural Materials: Properties, Microstructure and Processing), A361 (2003) 191-197.

[6] X.Z. Qin, J.T. Guo, C. Yuan, J.S. Hou, H.Q. Ye, Materials Letters, 62 (2008) 2275-2278.

[7] S.T. Wlodek, M. Kelly, D.A. Alden, in, TMS, Warrendale, PA, USA, 1996, pp. 129-136.

[8] T. Sugui, W. Minggang, L. Tang, Q. Benjiang, X. Jun, Materials Science and Engineering A, 527 (2010) 5444-5451.

[9] R.J. Mitchell, C.M.F. Rae, S. Tin, Materials Science and Technology, 21 (2005) 125-132.

[10] P.Villars, ASM International, 1997.

[11] K.R. Bain, M.L. Gambone, J.M. Hyzak, M.C. Thomas, Proceedings of the International Symposium on Superalloys, (1988) 13-22.

[12] D. Locq, P. Caron, S. Raujol, F. Pettinari-Sturmel, A. Coujou, N. Clement, Superalloys 2004. Proceedings of the Tenth International Symposium on Superalloys (2004) 179-187.

[13] P.R. Bhowal, E.R. Wright, E.L. Raymond, Metallurgical Transactions A (Physical Metallurgy and Materials Science), 21A (1990) 1709-1717.

[14] N.J. Hide, M.B. Henderson, P.A.S. Reed, SUPERALLOYS 2000. Proceedings of the Ninth International Symposium on Superalloys, (2000) 495-503.

[15] J. Telesman, P. Kantzos, J. Gayda, P.J. Bonacuse, A. Prescenzi, Superalloys 2004. Proceedings of the Tenth International Symposium on Superalloys (2004) 215-224.

[16] J. Telesman, T.P. Gabb, A. Garg, P. Bonacuse, J. Gayda, Superalloys 2008, (2008) 807-816.

[17] E. Andrieu, R. Molins, H. Ghonem, A. Pineau, Materials Science and Engineering A, A154 (1992) 21-28.

[18] H. Ghonem, D. Zheng, Materials Science and Engineering A (Structural Materials: Properties, Microstructure and Processing), A150 (1992) 151-160.

[19] M. Gao, D.J. Dwyer, R.P. Wei, Scripta Metallurgica et Materialia, 32 (1995) 1169-1174.

[20] A.K. Koul, R. Thamburaj, Metallurgical Transactions A (Physical Metallurgy and Materials Science), 16A (1985) 17-26.

[21] D. Turan, D. Hunt, D.M. Knowles, Materials Science and Technology, 23 (2007) 183-188.

[22] E. Andrieu, A. Pineau, Journal de Physique IV (Proceedings), 9 (1999) 3-11.

[23] R. Molins, J.C. Chassaigne, E. Andrieu, Materials Science Forum, 251-254 (1997) 445-452.

[24] R. Molins, G. Hochstetter, J.C. Chassaigne, E. Andrieu, Acta Materialia, 45 (1997) 663674. 
[25] R.G. Baker, J. Nutting, Iron and Steel, 32 (1959) 606-612.

[26] G. Thomas, J. Nutting, Institute of Metals -- Journal, 86 (1957) 7-14.

[27] The Journal of the institute of metals; Discussion, 91 (1963-64) 153.

[28] H. Gleiter, E. Hornbogen, Materials science and engineering, 2 (1968) 285-302.

[29] E. Grant, A. Porter, B. Ralph, Journal of Materials Science, 19 (1984) 3554-3573.

[30] A. Porter, B. Ralph, Journal of Materials Science, 16 (1981) 707-713.

[31] R.D. Doherty, Metal Science, 16 (1982) 1-13.

[32] G.W. Lorimer, R.B. Hicholson, Acta Metallurgica, 14 (1966) 1636.

[33] G.C. Wood, F.H. Stott, Materials Science and Technology, 3 (1986) 519-530.

[34] L.L. Shreir and R.A. Jarman and G.T. Burstein, Corrosion, Butterworth-Heinemann Ltd, Oxford, 1963.

[35] S. Lozano-Perez, Y. Huang, R. Langford, J.M. Titchmarsh, Electron Microscopy and Analysis 2001. Proceedings, 5-7 Sept. 2001, IOP Publishing, Bristol, UK, 2001, pp. 191194.

[36] D.M. Longo, J.M. Howe, W.C. Johnson, Ultramicroscopy, 80 (1999) 69-84.

[37] F.A. Stevie, R.B. Irwin, T.L. Shofner, S.R. Brown, J.L. Drown, L.A. Giannuzzi, Characterization and Metrology for ULSI Technology. 1998 International Conference, 23-27 March 1998, AIP, USA, 1998, pp. 868-872.

[38] G.V. Samsonov, The oxide handbook, Plenim Publishing Company, Ltd, London, 1973, pp. 23. 